Revista de Antropología Social

ISSN: 1131-558X

http://dx.doi.org/10.5209/RASO 59432

\title{
Los viajes y los dilemas del parentesco yaminawa (Amazonía peruana)
}

\section{Laura Pérez Gil ${ }^{1}$}

Recibido: 30 de mayo de 2017 / Aceptado: 30 de octubre de 2017

Resumen. Sea para visitar a parientes radicados en aldeas lejanas, o sea para ir a conseguir trabajo a otros lugares o a comprar mercancías en la ciudad, los Yaminawa parecen estar impelidos a un continuo desplazarse. Argumento en este texto que este movimiento incesante por un espacio definido antes como social y afectivo que como geográfico, tiene como motor la experiencia dilemática del parentesco, que presenta dimensiones tanto productivas como sociales y afectivas. A partir de la etnografía de estos dilemas, el texto plantea consideraciones sobre el significado de la Comunidad Nativa - como entidad territorial y social jurídicamente definida — para los Yaminawa.

Palabras clave: Amazonía peruana; parentesco; viajes; yaminawa.

\section{[en] Travels and kinship dilemmas among Yaminawa (Peruvian Amazon)}

\begin{abstract}
Yaminawa seem impelled to a constant displacement, sometimes to visit relatives living in distant villages, sometimes to get some temporary employment and to buy goods in town. In the present article, I argue that this incessant movement along a socially and emotionally (rather than geographically) conceived space has a dilemmatic experience of kinship as its driving force. This experience of kinship has productive and social dimensions as well as emotional ones. This text presents an ethnographical description of such dilemmas and raises some considerations about the meaning Yaminawa give to the concept of Comunidad Nativa as a territorially, socially and legally defined entity.
\end{abstract}

Keywords: Peruvian Amazonia; kinship; travels; yaminawa.

Sumario: 1. Introducción. 2. El "problema yaminawa". 3. Poniendo tierra de por medio. 4. Viajando. 5. Comprar "sus cositas". 6. Hijos pródigos. 7. Entre la aldea y la ciudad. 8. Los viajes y la experiencia del parentesco. 9. ¿Comunidad nativa? 10. Referencias bibliográficas.

Cómo citar: Pérez Gil, L. (2018). Los viajes y los dilemas del parentesco yaminawa (Amazonía peruana), en Revista de Antropología Social 27(1), 49-71.

1 Programa de Pós-Graduação de Antropologia - Universidade Federal do Paraná. lauranawa@gmail.com 


\section{Introducción}

En septiembre de $2013^{2}$, tras diez años desde mi última visita a la región, llegué a la ciudad de Atalaya ${ }^{3}$ con la intención de, desde allí, dirigirme a la comunidad yaminawa ${ }^{4}$ de Raya, localizada a tres días de viaje río arriba, en el río Mapuya. Cuando, tras varios días, conseguí localizar a algunos Yaminawa radicados en Atalaya, me llevé una sorpresa ante su insistencia de que no me molestara en ir al Mapuya porque la comunidad estaba vacía y ya casi nadie vivía allí. Desde luego, estaba claro que algunos cambios habían ocurrido, dado que encontré viviendo en Atalaya a varias de las familias que en 2003 lo hacían en Raya. Durante el período en que realicé la mayor parte de mi trabajo de campo, entre 2000 y 2003, tan solo una mujer yaminawa, casada con un hombre yine $^{5}$, vivía en Atalaya. De cualquier forma decidí surcar hasta el Mapuya, donde me encontré con que, efectivamente, la población había disminuido un poco - de 81 personas aproximadamente en 2003 a 72 en $2013^{6}$. No es posible dar nunca una cifra exacta porque la situación varía muy rápidamente en función de los continuos desplazamientos. Sin embargo, si es verdad que a primera vista la situación no me pareció tan radical como me la habían dibujado, cuando empecé a conversar con la gente de Raya, muchos de ellos me explicaron que, de hecho, habían estado viviendo varios años en otros lugares y solo se habían vuelto a restablecer en Raya hacía poco. Durante años habían quedado en la aldea tan solo unas pocas personas, en su mayoría ancianos. Así que la comunidad del Mapuya había pasado por un periodo largo de encogimiento hasta su casi desaparición, y ahora se encontraba de nuevo en otro de distensión. Algunas personas habían estado en ciudades como Lima o Iquitos; otras habían estado viviendo durante años en la población mestiza de Floresta, en la desembocadura del Inuya, río abajo; varios jóvenes habían estado trabajando en la región de ceja de selva por Satipo y Mazamari. Para completar el cuadro, diversas familias que vivían en 2003 en Raya se habían trasladado a las ciudades amazónicas de Atalaya, Sepahua o Pucallpa. Algunas habían dicho que era un simple viaje y que volverían en breve; había quien había dejado incluso sus casas y gallinas al cuidado de los suegros, previendo la vuelta, pero el caso es que ya llevaban años fuera. La caída de población en Raya debido a estas continuas mudanzas, y especialmente el escaso número de niños, estaban teniendo consecuencias nada deseables desde el punto de vista de sus habitantes, ya que empezaba a estar en riesgo la existencia de la escuela, y durante los dos meses que estuve allí

2 La mayor parte de mi trabajo de campo fue realizado en 2000, 2001 y 2003, antes y durante el doctorado, gracias a los recursos del proyecto TSEMIN y a una beca de doctorado del CNPq. Recibí igualmente fondos de Legs Lelong (CNRS) en 2005. La visita de 2013 fue realizada en el marco de una investigación de pos doctorado financiada también con una beca del CNPq. Agradezco a esta institución por su apoyo continuado. Una primera versión de este texto fue presentada en el Panel "La comunidad nativa in Peruvian Amazonia: Historical and Ethnographic Perspectives” en la IX Reunión de SALSA. Agradezco a los organizadores y participantes del panel por las discusiones planteadas y sus contribuciones.

3 Atalaya, localizada en la confluencia entre el Urubamba, el Ucayali y el Tambo, es el centro urbano más cercano a Raya. Es la referencia para los Yaminawa del Mapuya en lo que se refiere a cuestiones administrativas, a la búsqueda de recursos terapéuticos externos a la aldea — biomédicos pero sobre todo los ofrecidos por diversos tipos de especialistas rituales_-, o a la compra de mercancías.

4 Existen diferentes grafías con las cuales se les conoce, de las cuales Yaminahua es la más frecuente en Perú, Jaminawa y Yaminawá las utilizadas generalmente en Brasil, y Yaminawa en Bolivia. Utilizo "yaminawa" porque es la forma coherente con la grafía que uso para escribir la lengua yaminawa.

5 Los Yine, también conocidos como Piro, son un pueblo de lengua arawak localizado, principalmente, en las cuencas de los ríos Urubamba, Madre de Dios y Las Piedras.

6 En ambos casos un poco menos de la mitad son niños. 
en 2013 comenzaron a surgir propuestas para atraer a los amahuaca ${ }^{7}$ de los caseríos de río arriba para evitar esta situación.

Estos movimientos de dilatación y contracción del cuerpo aldeano no son, exclusivamente, efecto de procesos contemporáneos. Townsley describe una dinámica social, antigua, marcada por la oscilación entre momentos en los que todas las familias se juntaban en las malocas colectivas y otros, durante la temporada de seca, en los que se dispersaban y residían en viviendas individuales (Townsley, 1994: 322). Estos movimientos eran guiados por el ciclo productivo, pero tenían, obviamente, consecuencias sociológicas. Las formas, la temporalidad y el ámbito socio-geográfico donde ocurren los desplazamientos son, en parte, diferentes, pero este continuo circular parece ser, en el pasado y en el presente, un aspecto cíclico y central de la sociabilidad yaminawa.

Estar en movimiento es una de sus características, frecuentemente notada, no sin cierto fastidio, por los etnólogos que han estado entre ellos. El viaje, el camino, las expediciones, un constante trasladarse de un lugar a otro... son elementos perseverantes en las etnografías dedicadas a los Yaminawa o grupos afines (Townsley, 1994; Calavia, 2004, 2006, 2007; Carid 2007; Feather, 2010; Hewlett, 2013). Mi objetivo en este texto es analizar estos desplazamientos, en su diversidad y heterogeneidad, como aspectos inherentes a la dinámica sociológica yaminawa y que, aún teniendo motivaciones económicas, están enraizados en la forma de concebir y vivir el parentesco.

Los Yaminawa del Mapuya, a los que me refiero específicamente aquí, forman parte de un conjunto mayor junto con varias otras aldeas establecidas en el Yuruá ${ }^{8}$. Digo que forman parte de un mismo conjunto porque reconocen entre ellos lazos de parentesco y comparten una historia reciente común. El contacto permanente con la sociedad nacional de ese conjunto data de principios de los años 60 y ocurrió en la región del alto Mapuya (Pérez Gil, 2011). Poco después, algunas familias se trasladaron al Huacapistea, afluente del Yuruá, con la intención de, nuevamente, apartarse de los blancos, negándose a trabajar para los madereros 9 . Dos décadas después, ante la amenaza de la llegada de los "terrucos" " — como llaman a los miembros de Sendero Luminoso-, un nuevo contingente de familias se reunió con aquellas en el Yuruá, restando un grupo bastante menor en el Mapuya. En total existen hoy, en Perú, cuatro Comunidades Nativas $\mathrm{CCNN}$ - demarcadas a favor de los Yaminawa que pertenecen a este conjunto: dos en

\footnotetext{
Los amahuaca son también de habla pano y han ocupado tradicionalmente territorios contiguos a los habitados por los Yaminawa. Ambos grupos han mantenido tradicionalmente relaciones que han oscilado entre la guerra y la alianza. Actualmente se encuentran localizados principalmente en el Inuya y el alto Mapuya.

8 Son alrededor de ocho, distribuidas a lo largo del Yuruá en los territorios demarcados de dos Comunidades Nativas (CCNN): El Dorado y San Pablo. Hay otros colectivos conocidos con el mismo etnónimo en las proximidades de Sepahua — procedentes del Purús - en el Pando (Bolivia), en el Acre (Brasil). Entre todos ellos existe tal homogeneidad cultural y lingüística que permite suponer una relación histórica. Sin embargo, los únicos con los que los habitantes de Raya reconocen lazos actuales son las familias del Yuruá. La Comunidad Nativa es la figura administrativa y jurídica por medio de la cual se tornan efectivos los derechos territoriales de los pueblos indígenas. Retomaré su análisis al final del artículo. Su equivalente en Brasil es la Terra Indígena.

9 Refiriéndose a este mismo desplazamiento, Townsley (1994:267) menciona que la razón fue aislarse para protegerse de las epidemias que les afectaron poco después del contacto. En los relatos que me hicieron, sin embargo, siempre enfatizaron que fue el rechazo al trabajo con los madereros lo que marcó una disensión interna entre los que se fueron y los que optaron por quedarse, aunque no llegó a producirse un conflicto abierto. El rechazo a los madereros y caucheros es también la razón que, en las narrativas que me fueron relatadas, explica la actitud de los jefes yaminawa que, hasta 1964, habían rehusado sistemáticamente establecer relaciones con los no indígenas (Pérez Gil, 2011).

10 Aunque no llegaron a adentrarse en el Mapuya hasta Raya, sí es cierto que en 1991 ocuparon la aldea amahuaca de San Martín, en el Inuya (Hewlett, 2013:124), a algunas horas río abajo de Raya.
} 
el Yuruá, una en el Mapuya y otra en el Huacapistea. Esta última fue abandonada por los Yaminawa y está actualmente ocupada por familias ashéninka ${ }^{11}$ (Lenaerts, 2002).

Pero para tener una visión completa de la configuración de este conjunto, no basta con fijarse en las CCNN. Muchas familias se han trasladado a otros lugares: comunidades ribereñas donde conviven indígenas y no indígenas, como lo son Floresta en el Inuya o Breu en el Yuruá; ciudades como Atalaya, Pucallpa o Sepahua; y enclaves próximos a las ciudades donde se han creado aldeas que no están en territorios demarcados. El ejemplo que conozco de este tipo de situación es el de la aldea localizada en el Km 21 de la carretera de Pucallpa, creada al lado de un basural ${ }^{12}$. Para completar el cuadro de la distribución espacial de los Yaminawa hay que mencionar también a personas, no tanto familias, que por diversas razones se han trasladado a ciudades como Satipo, Mazamari o incluso Lima. En general, la razón por la que lo hacen es por trabajo o, en el caso de algunas mujeres, por haberse casado con hombres no yaminawa que las han llevado a vivir con ellos - no tengo noticias de ningún caso inverso.

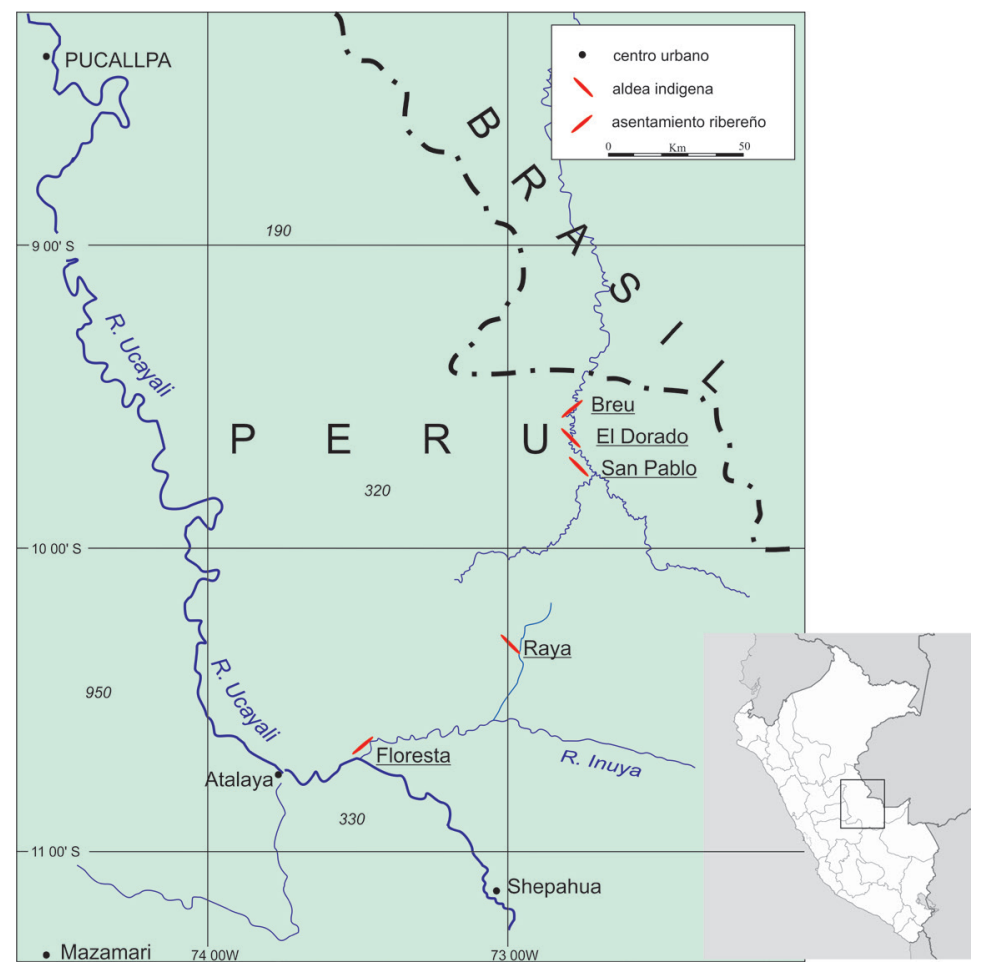

Región de circulación de los Yaminawa ${ }^{13}$.

11 Ashéninka y Ashaninka, a los que hago referencia también a lo largo del texto, forman un bloque relativamente homogéneo dentro del conjunto de los arawak subandinos. Su territorio tradicional es la Selva Central del Perú, aunque han ido desplazándose progresivamente hacia el este, llegando a establecerse en tierras acreanas (Brasil). La denominación Campa, por la que han sido conocidos durante mucho tiempo, ha sido desechada por tener una connotación despreciativa (Lenaerts, 2002). Según datos del Ministerio de Cultura de Perú, entre ambos subgrupos suman alrededor de 130.000 personas, de las cuales aproximadamente el 89\% es Ashaninka.

12 En este local, que visité brevemente en 2013 y donde encontré varias personas que entre 2000 y 2003 vivían en Raya, los Yaminawa se dedican a trabajar recogiendo materiales reciclables en el basural.

13 Mapa elaborado por Fabio Parenti (PPGA-UFPR), a quien agradezco por ello. 
A pesar de la distancia, la mayor parte de las personas continúa manteniendo contacto con sus familiares y, en general, visitan de vez en cuando las comunidades donde viven sus parientes. Existe, de hecho, una intensa circulación de personas y de noticias en el seno de esta extensa red, para lo cual el uso de la radio en las aldeas y del teléfono móvil, recientemente introducido en el medio urbano, tiene un papel fundamental. Una de las principales preocupaciones cotidianas de los Yaminawa es saber sobre los parientes que están lejos, especialmente si hace tiempo que no se tienen noticias. Cuando una persona sale de esta red de comunicación, no tardan en surgir historias, muchas veces macabras, sobre su muerte segura. Durante el trabajo de campo que realicé en 2013, acompañé a Hustuma, una mujer yaminawa de entre 45 y 50 años, actualmente residente de Atalaya, en sus consultas a diversos curanderos de esta población. Aparte de saber sobre infidelidades de su ex marido o la razón de malestares y enfermedades de ella o sus hijos, una de sus principales inquietudes era saber, por medio de técnicas de adivinación, lo que había ocurrido con un cuñado del que no había tenido noticias en varios meses. La versión que circulaba era que había sido secuestrado y asesinado por narcoterroristas con los que supuestamente andaba mezclado. También a mí me habían dado por muerta, y según las noticias absolutamente certeras que les habían llegado, había sido canibalizada por los terribles cashibo en tierras brasileñas. Fuera del ámbito del parentesco, las perspectivas no son muy halagüeñas; se presume la muerte.

La configuración descrita, que implica, por un lado, la continua dispersión de las familias y, por otro, la manutención y reactualización de los lazos de parentesco a pesar del distanciamiento geográfico, entraña y refleja una tensión entre tendencias y movimientos centrífugos y centrípetos, y una experiencia del parentesco marcada por los dilemas. La expresión ëwë yura, usada tanto para hablar del propio cuerpo como para referirse a los parientes próximos ${ }^{14}$, remite a una idea de cuerpo compartido: son cuerpos que se generan, constituyen y desarrollan mutua y recíprocamente. Ello significa que participan de las mismas substancias (fisiológicas, alimentarias...), pero también que los unos son necesarios para activar las capacidades productivas y reproductivas de los otros (Pérez Gil, 2010). Esta noción de un cuerpo compartido implica, por ello mismo, que está fragmentado y proyectado en el tiempo y en el espacio en esa configuración dispersa (Carid Naveira, 2007).

\section{El "problema yaminawa"}

Si en Perú el caso de los Yaminawa no se destaca especialmente, en Brasil ${ }^{15}$ constituyen "un problema" precisamente por sus continuos desplazamientos a la ciudad donde se quedan por largos periodos, pasando hambre y mendigando, lo que es considerado por las autoridades y miembros de ONGs como prueba de un estado de anomia y desestructuración, resultado "evidente" de la "pérdida de cultura". Son una piedra en el zapato para un gobierno, el del estado del Acre, que viene construyendo a lo largo de los últimos años una política de desarrollo sustentable en el que los

14 Ëwë es el posesivo de primera persona, y yura significa cuerpo —un cuerpo vivo. La expresión puede traducirse tanto por "mi cuerpo" como por "mi pariente", dependiendo del contexto"

15 En el estado del Acre, en Brasil, existen varias comunidades yaminawa localizadas en ocho Tierras Indígenas diferentes, algunas de las cuales comparten con otros pueblos. 
pueblos indígenas tienen un papel simbólico y político fundamental en la medida en que encarnan la conexión propuesta, y presupuesta como intrínseca, entre las culturas tradicionales y la conservación ambiental (Ferreira, 2014). Los indios en la ciudad que se resisten a volver a los territorios demarcados a su favor y que, a ojos de las autoridades y los no-indígenas en general, no hacen sino mendigar, emborracharse, enfermar y dejar el tiempo pasar en el simple mirar las calles, constituyen, de hecho, un desafío al modelo que presupone al indígena como un ser, en esencia, próximo a la selva y representante de una "tradición" cultural exótica y primera ${ }^{16}$. Los Yaminawa, en el Acre, son el paradigma de este tipo de indígena incómodo y poco productivo en términos de una simbología política. Su presencia en la ciudad es percibida como una incongruencia, un oxímoron, no sólo porque conceptualmente el ser indígena y la urbe son considerados como mutuamente excluyentes, sino también porque la ciudad es un medio considerado hostil para el indígena, en el cual normalmente pasan por toda clase de necesidades y sufrimientos de los cuales estarían libres en sus aldeas.

Tomando esta situación como objeto de reflexión, Calavia $(2004,2015)$ ha mostrado que los procesos de demarcación territorial no tienen en cuenta las nociones indígenas de territorialidad. En contraste con un concepto sincrético del territorio donde las relaciones se constituyen a partir del mismo, la territorialidad yaminawa se define, según este autor, como un mapa carnal conformado por lugares-sujeto antes que por lugares-objeto. El territorio - en cuanto espacio significativo que forma parte de la experiencia de vida de las personas - lo es en la medida en que en él están insertos sujetos, principalmente parientes, con los cuales existe una relación. El énfasis colocado por el autor en la sociología como dato que antecede al espacio geográfico se aplica perfectamente a los Yaminawa en Perú, por lo menos al conjunto del Mapuya/Yuruá. Y es esta dimensión sociológica del territorio —una sociología impregnada de afectividad, hay que decir - lo que nos ayuda a entender tanto lo que desencadena los viajes yaminawa, como sus formas.

Es necesario puntualizar, ya de antemano, que no es posible reducir a una única motivación los desplazamientos. Distinguiré, con fines analíticos, dos tipos: por un lado, aquellos traslados que son consecuencia de una fisión, y que implican la separación de grupos de familias que están emparentadas y que antes vivían juntas; y por otro, aquellos que asumen la forma de un viaje, que se inician con la perspectiva de un retorno, aunque en muchas ocasiones este se posponga indefinidamente.

\section{Poniendo tierra de por medio}

La dinámica sociopolítica yaminawa, como la de otros varios grupos pano, se caracteriza, entre otras cosas, por una continua sucesión de procesos de fisión y fusión, que ha sido descrita no sólo respecto de los Pano del Purús, sino también de otros conjuntos como el Mayoruna (Santos Granero y Barclay, 1998). En determinadas ocasiones, como es el caso del desplazamiento al Huacapistea y posteriormente al Yuruá que mencioné anteriormente, la dispersión no implica conflictos. Sin embargo, en una buena parte de los casos sí es producto de ellos.

16 Una entrevista en televisión con el ex gobernador del Acre, Jorge Viana, es un buen ejemplo de este discurso: https://www.youtube.com/watch?v=fuMG9pkKx1M. 
La multiplicidad de etnónimos que engloba el de yaminawa es resultado de esta historia turbulenta. Entre otros grupos pano existen autodenominaciones que suelen ser glosadas como "gente" o "la gente verdadera" los etnónimos formados con los sufijos - nawa $\mathrm{o}-b o^{18}$ a los que se atribuye un origen exógeno. Los Yaminawa, sin embargo, no reivindican ninguna autodenominación de este tipo. Tienen plena conciencia de que "yaminawa" es un nombre atribuido por los mestizos y lo explican por el hecho de que durante el contacto pedían continuamente yami (hachas de metal); sin embargo, asumen este término como etnónimo sin ningún problema, al mismo tiempo que explican que engloba varios otros como bashunawa, nixinawa, txaunawa, etc., con los que también se identifican. No es raro que cada uno explique sus orígenes, o los de otras personas, aludiendo a que son, por ejemplo, de padre amahuaca y madre txitonawa, de padre bashunawa y madre nixinawa, o de madre yaminawa y de dos padres: txitonawa y ashaninka. Estas explicaciones sobre los orígenes de cada uno, y especialmente la memoria precisa que se tiene sobre ellos, reflejan una historia marcada por esta sucesión de fusiones y fisiones entre conjuntos de familias que forman un contínuum lingüístico, cultural y sociopolítico $^{19}$. La memoria sobre el parentesco compartido opera paralelamente a la memoria de los conflictos: ora se recuerdan los lazos de parentesco, aunque sean antiguos y en ocasiones ni siquiera vividos hasta el momento por las personas implicadas; ora la memoria sobre antiguas desavenencias explica las posiciones adoptadas cuando estalla un enfrentamiento interno o, incluso, se blanden para justificar el ejercicio de la violencia. Las líneas de fractura nunca son inequívocas ni previsibles, en gran medida porque cada persona puede reivindicar diferentes conexiones. Del grado de intensidad del conflicto dependerá tanto la distancia geográfica que se generará, como la posibilidad de reatar y continuar cultivando los lazos existentes una vez los ánimos se hayan calmado. En los casos más dramáticos, la separación entre dos grupos de familias es radical y permanente, o dura décadas - como ocurrió antes del contacto-; en otras, implica simplemente la creación de nuevos caseríos a tan sólo algunos kilómetros del anterior y sin que ello conlleve cortar las relaciones entre las familias enfrentadas.

Un ejemplo claro de esta dinámica y del papel de la memoria, tanto en un sentido como en otro, es la relación entre los Yaminawa y los Txitonawa. Ambos grupos se conocieron cuando todavía no tenían relaciones permanentes con el mundo no indígena y establecieron una alianza a través de varios matrimonios. Sin embargo, cuando algunos Yaminawa comenzaron a morir, el jefe txitonawa fue culpado, acusándosele de haberlos matado por medio de brujería. El conflicto llegó a su punto crítico cuando, tomado por la cólera al ver morir a sus seres queridos y sabiéndose él mismo víctima, el jefe yaminawa empezó a disparar indiscriminadamente a los Txitonawa con su carabina. El resultado fue que ambos grupos se separaron, calculo

17 Por ejemplo, los grupos conocidos durante mucho tiempo como Cashibo y Cashinahua, términos ambos que significan "gente murciélago", reivindican como etnónimos, respectivamente, los términos Uni y Huni Kuin, que significan literalmente "gente", "hombres verdaderos" (Frank, 1994:139; Kensinger, 1998: 6).

18 Ambos sufijos operan como colectivizadores, pero nawa tiene la peculiaridad de que significa también "extranjero". Así, cada etnónimo formado con este sufijo carga el punto de vista de la alteridad que lo creó. No se generaron como autodenominaciones, sino como términos para designar a los otros.

19 El límite de espacio no permite aquí relatar casos específicos. Varios de ellos, tanto de separación como de establecimiento de nuevas o antiguas alianzas, son relatados y detallados en Pérez Gil (2006) y Carid Naveira (2007). 
que hacia la mitad del siglo XX. Algunas décadas después, en 1995, varias familias txitonawa fueron contactadas en el alto Mapuya, y los Yaminawa, que ya habían "salido del monte" tres décadas atrás, fueron llamados por los madereros para actuar como mediadores. Enseguida varios se reconocieron como parientes, no tanto porque se conocieran personalmente, sino por las historias que les habían contado sus respectivos padres y abuelos. En función de esos lazos de parentesco, los Txitonawa fueron acogidos en la aldea de Raya y, posteriormente, varias familias se trasladaron y establecieron en las comunidades yaminawa del Yuruá, a pesar de la existencia de un territorio demarcado a su favor. Nuevamente, hubo varios matrimonios entre Yaminawa y Txitonawa. Y, sin embargo, la memoria de las muertes antiguas continuó vigente, llegando a un momento álgido y trágico cuando una mujer y varios niños txitonawa fueron asesinados en el Mapuya en el 2000. Los culpables se justificaban diciendo que actuaron movidos por un sentimiento de venganza a causa de los asesinatos perpetrados en el pasado por otros Txitonawa. Y en el Yuruá, sin embargo, Txitonawa y Yaminawa continúan conviviendo, hasta el punto de que algunos de los hermanos del hombre que promovió los asesinatos en el Mapuya han establecido una alianza con el contingente txitonawa y han creado una nueva aldea.

En circunstancias menos violentas, pequeñas fisiones se producen con una cierta frecuencia en el seno de una aldea. Se trata de peleas entre vecinos a partir de las cuales alguno de los implicados decide irse a vivir un poco más distante, aunque sin dejar el territorio y permaneciendo en la comunidad. Se trata, en estos casos, de poner un poco de distancia tras una desavenencia ${ }^{20}$. Actualmente, entre los motivos que varios hombres yaminawa alegan están, por ejemplo, la mayor facilidad para criar gallinas o cerdos, o el "no ser molestado", pero el hecho es que todos los movimientos de este tipo de que fui testigo tuvieron como desencadenante peleas ocurridas durante las masateadas ${ }^{21}$. Estas peleas generan siempre la intención de irse, aunque eventualmente, una vez pasada la borrachera y calmados los ánimos, la amenaza no se cumpla (Carid Naveira y Pérez Gil, 2013). Ya entre las razones invocadas para explicar el restablecimiento en el núcleo central de la aldea, suele estar, como ocurre también en otros casos (Killick, 2008; Hewlett, 2013), la necesidad de facilitar el acceso de los niños a la escuela. No dejan, en cualquier caso, de ser explicaciones, tanto las dadas al irse como las ofrecidas al volver, que suenan un tanto peregrinas — quizá consideradas apropiadas para ser ofrecidas al etnólogo- dado el poco impacto que los aspectos mencionados tienen en la vida cotidiana.

Las fisiones son, en gran medida, responsables de la configuración en red, fragmentada y dispersa, que he descrito anteriormente. Una vez establecidas aldeas o caseríos en otros lugares, se constituyen en polos de atracción para personas que deciden instalarse allí, sea por afinidad con alguien, sea por matrimonio o porque consideran las condiciones más favorables. Esta dispersión es una de las condiciones

20 A diferencia del caso de los Amahuaca (Hewlett, 2013), las peleas que acaban con la muerte de alguien ocurren entre personas que no son parientes, o lo son por alianza, como en el caso de los Txitonawa. Si los conflictos entre parientes no son raros, sí lo es que resulten en muerte violenta. Sin embargo, sí son frecuentes las acusaciones de brujería entre parientes próximos, pero estas en general tienen otras causas diferentes a las que están en el origen de las disputas abiertas (Pérez Gil, 2006).

21 Se trata de fiestas colectivas que giran en torno de la ingestión del masato, una bebida fermentada elaborada a base de yuca, aunque hace ya unos años que se introdujo también el consumo del "trago", una bebida alcohólica destilada. El masato fue introducido tras el contacto, y los Yaminawa lo asocian sobre todo a los Ashaninka. 
de la movilidad yaminawa: visitar a los parientes que están lejos es uno de los principales motores explícitos de los viajes.

\section{Viajando}

La centralidad de la idea del viaje entre los Yaminawa no se expresa únicamente en su tendencia a desaparecer de repente y continuamente de la aldea, tan de repente como vuelven a aparecer, sino que se revela también en otras dimensiones. Como han destacado otros autores - y no voy aquí a detenerme en estos aspectos - el tema del viaje aparece recurrentemente en los mitos o en las descripciones de las visiones de ayahuasca (Calavia, 2004; 2007; Feather, 2012). Se trata, así, tanto de viajes que recorren la topografía sociocosmológica horizontal, como de desplazamientos verticales, durante los cuales se visita a los parientes muertos que viven en el cielo, los wëro mëxë dawa (Calavia, 2006:355). Asociado al viaje, se destaca el concepto de camino, no solo los que atraviesan la aldea, o sutilmente los bosques, sino también los que se trazan al entonar los cantos chamánicos (Townsley, 1993; Déléage, 2009:256-257).

A partir del análisis del papel de los viajes en los mitos, Oscar Calavia interpreta las odiseas yaminawa, aparentemente desordenadas y anómicas, como "viajes estructurantes". Este papel estructurante del viaje se da por dos razones, aunque el autor se concentra en la segunda: en primer lugar, porque mantienen vivas las relaciones con los parientes lejanos; en segundo lugar, porque es uno de los mecanismos para la constitución y gestión de las distancias entre la semejanza - yura - y la alteridad - nawa - de tal forma que la separación entre parientes que viven distantes sea lo suficientemente amplia como para crear diferencia ${ }^{22}$, y posibilitar así los matrimonios, pero no tan grande que imposibilite su recorrido (Calavia, 2002; 2004; 2006: 360-361).

En este sentido, los viajes son mecanismos para la producción y la actualización de las relaciones de parentesco en diferentes dimensiones, tanto materiales, como sociológicas y afectivas. Entre los Yaminawa del Mapuya, la motivación alegada con más frecuencia para explicar los viajes realizados o en proyecto es visitar a los seres queridos que están lejos: padres que van a la aldea donde viven sus hijos ya adultos; hermanas que visitan a sus hermanos; hijas casadas con un mestizo y que viven en Mazamari o Pucallpa que sienten deseos de ver a sus madres... Y en los relatos, reflexiones y proyectos de estos desplazamientos, el motor explícito son los afectos: el pensar en el otro genera siempre un sentimiento de melancolía y de añoranza. El

22 Efectivamente, las prácticas inherentes a la corresidencia, como el compartir alimentos y espacios, generan un exceso de similitud entre las personas de una aldea, ya que los cuerpos están siendo producidos en contigüidad. Esta es una característica verificada en los sistemas de parentesco de las sociedades de las Tierras Bajas de América del Sur que ha llevado a reconsiderar el carácter de la consanguinidad. Descripciones etnográficas y formulaciones teóricas recientes enfatizan su carácter construido, contraponiéndose a un modelo clásico considerado como derivado de las (etno)concepciones occidentales, que asume la consanguinidad como la dimensión biológica, natural y dada del parentesco. Una formulación sintética sobre el asunto se puede encontrar en Viveiros de Castro (2009). En el caso de los Yaminawa, la percepción de un exceso de similitud entre corresidentes hace que, aunque en términos de reglas y clasificaciones de parentesco, no haya impedimento para el matrimonio, los jóvenes que han crecido juntos no se conciban entre sí como la mejor opción para casarse. Lo más habitual es que busquen sus parejas en otras aldeas yaminawa y, más recientemente, entre otros pueblos indígenas o entre no indígenas. Si el casamiento preferencial tradicional es con los bibii — primos/as cruzados/as - , esta tendencia se ve flexionada por una exogamia aldeana marcada. 
pensar - xinai - en aquellos que están lejos es algo presente en el cotidiano, un pensar intrínsecamente asociado a la tristeza — xinai bitsai- y que se manifiesta especialmente, aunque no únicamente, cuando las personas se emborrachan. Es frecuente que durante las masateadas emerjan voces entonando los cantos -improvisados y autobiográficos - yama yama, o incluso los lloros, que evocan a los seres queridos que no están juntos porque viven en otros lugares o porque han muerto ${ }^{23}$. Pero como señala Miguel Carid (2007), el irse plantea siempre un dilema, porque el emprender un viaje para visitar a alguien entraña inevitablemente dejar atrás, aunque sea temporalmente, a otras personas. Estar con todos al mismo tiempo es imposible, y esa afectividad dilemática, inacabable y siempre presente, opera como combustible para los desplazamientos, tanto los horizontales como los verticales - los muertos son también añorados, a pesar de la carga de otredad y peligrosidad que adquieren (Carneiro da Cunha, 1978).

\section{Comprar "sus cositas"}

Además de las visitas a los parientes, existen varias otras razones por las que los Yaminawa viajan, especialmente a la ciudad: consultar a un curandero, resolver un problema administrativo, o, una de las más frecuentemente mencionadas, poder comprar objetos manufacturados considerados de primera necesidad, "mis/sus cositas", como lo expresan en español. Desde la época del contacto, la principal fuente de recursos fue el trabajo para los madereros. Sin embargo, actualmente, con el aumento de la fiscalización sobre la extracción maderera y la retirada de las empresas del Mapuya, esta actividad ha sido en gran medida sustituida por la venta de productos de la chacra y del monte. A veces se produce un excedente de maíz o se planta arroz para venderlo en Atalaya; otras veces, antes de emprender un viaje se organiza una expedición de caza para vender en alguna comunidad mestiza río abajo la carne de los animales abatidos. Especialmente apreciados son los motelos, ya que estas tortugas terrestres se pueden llevar vivas a Atalaya y son vendidas rápidamente y a buen precio. La obtención de mercancías manufacturadas es una necesidad perentoria y una de las competencias que cualquier hombre debe ser capaz de desarrollar. Un hombre me explicaba durante una masateada que para que "tu hembra te quiera", tienes que ser capaz de comprarle "sus cositas", "pensar bien". El problema no es solo ganar el dinero, sino gastarlo adecuadamente comprando a la mujer y a los hijos lo que necesitan en vez de gastarlo todo emborrachándose en la ciudad. Aunque la lista de las cosas que se compran y se desean es amplia, aquello a lo que los Yaminawa se refieren con "mis/sus cositas" son artículos considerados básicos: jabón, ropa, sal, cartuchos, pilas, hachas, machetes y ollas principalmente. El carecer de esos objetos es entendido como "ser pobre". Los "antiguos" eran pobres porque solo tenían hachas de piedra y por ello solo podían hacer chacras pequeñas; eran "pobres" porque no tenían ropa y comían sin sal. De la misma forma que un hombre tiene la obligación de hacer una chacra y de cazar para sustentar a su familia, debe ser capaz de comprar "sus cositas". Ello implica un conjunto de desplazamientos río arriba -

23 Esta cuestión ha sido extensamente descrita y analizada por Miguel Carid Naveira (2007). Los yama yama giran en torno de diversas temáticas, pero la expresión de la tristeza relacionada con los parientes es una de las más frecuentes. 
donde es más fácil encontrar carne de caza - y río abajo, en dirección a la ciudad. Pero no es algo que el hombre haga solo, sino que envuelve a toda la familia, tanto en lo que respecta a la obtención de lo que se va a vender, como en la ida a la ciudad. En estos casos se trata de viajes relativamente cortos, aunque toda estancia en la ciudad es pasible de ser alargada por varios meses hasta que se consiga gasolina suficiente para el retorno, o por lo menos la falta de gasolina es frecuentemente la explicación dada a las estancias alargadas en la ciudad. Estos desplazamientos parecen hacer equivaler selva y ciudad en la medida en que ambos ámbitos constituyen fuentes de recursos y promueven acciones e interacciones entendidas en términos sociales específicos, necesarias para la inclusión de los actores en redes más amplias formadas por diversos tipos de seres y lugares (Alexiades, 2009). Sin embargo, eso no debe hacernos olvidar que también existen, desde el punto de vista yaminawa, diferencias significativas entre ellos. Vuelvo luego sobre este punto.

\section{Hijos pródigos}

En otras ocasiones, los viajes, de carácter más individual que familiar, implican estancias muy largas fuera de la aldea y lejos de la familia. Hoy en día - y ello ha ido en aumento - es frecuente, por ejemplo, que los jóvenes, tanto hombres como mujeres, aún solteros, realicen viajes a lugares lejanos y por un periodo de tiempo más extenso, sobre todo con el propósito de trabajar, de estudiar en alguna misión o de cumplir el servicio militar obligatorio. En los últimos años, tras la falencia de la extracción maderera en el Mapuya, varios jóvenes han comenzado a ir a la zona de Satipo y Mazamari, en la ceja de selva, para engancharse en el trabajo de la recolección de café y otros similares, o, en el caso de las mujeres, para ser contratadas en el trabajo doméstico. El trabajo en ciudades lejanas entre los hombres jóvenes responde a la necesidad de trabajar para tener una familia. Volvemos de nuevo aquí al punto anterior: el ser capaz de ganar dinero suficiente para poder comprar "las cositas" necesarias es una condición sine qua non para poder casarse, tener y mantener una familia.

Pero estos viajes individuales, largos y lejos de la familia, no son una novedad contemporánea. En sus relatos, muchos hombres más viejos — en este caso, me parece que eran experiencias exclusivamente masculinas - cuentan que cuando eran jóvenes vivieron por largas temporadas en territorio brasileño trabajando en la apertura de chacras o en lo que se terciara, o en ciudades como Pucallpa. Estos viajes son frecuentemente un asunto sobre el que les complace conversar.

El deseo de viajar y conocer otros lugares y la necesidad de obtener dinero son las razones para emprender estos viajes, y en eso las generaciones de jóvenes no se diferencian mucho de sus padres y abuelos. Lejos de hacer referencia a las imposiciones externas, estos viajes son descritos como resultado de motivaciones personales, y aunque nuevos condicionamientos hayan surgido, como la obligación de cumplir el servicio militar, nunca son determinantes. En general, los Yaminawa son especialistas en esquivar obligaciones, estatales o de cualquier otro tipo. Cuando una situación no es de su agrado, no dudan en "escaparse". Las jóvenes, en general, describen sus estancias en la ciudad como positivas y a quien se hizo cargo de ellas como personas que las apreciaban y las cuidaban. En las narraciones de los hombres jóvenes, sin embargo, aparecen frecuentemente situaciones de conflicto, sobre todo 
por causa de jefes que les exigían demasiado trabajo y no les trataban bien. El fin de estos periodos es frecuentemente la fuga: se escapan sin haber cumplido el contrato y llevándose el dinero que ya les han pagado.

Todos los relatos que varias mujeres y hombres yaminawa me han hecho a este respecto tienen dos puntos en común. En primer lugar, el viaje es una experiencia positiva en la que más que el trabajo que se debe realizar o el dinero que se gana aunque sea postulado como principal motivo, acaba no siendo mucho y de cualquier forma dura muy poco- , se destaca lo que se descubre: animales desconocidos; tecnologías inesperadas, como las escaleras mecánicas, el ascensor o internet; lugares abrumadores, como las montañas. Incluso en el caso de los que se escapan de su trabajo sin haber ganado gran cosa, se relata como una aventura, con divertimento, destacando la valentía e incluso la violencia con la que se trata al patrón desalmado y mezquino. En segundo lugar, se explica que tras haberse "acostumbrado" a vivir en ese medio extraño, sin conexión prácticamente con la familia, se vuelve no tanto por el deseo de rever a quienes se dejó, sino por el sufrimiento que la propia ausencia provoca en los seres queridos, sobre todo en las madres. "Volví porque me dijeron que mi mamá lloraba mucho", o "volví a Atalaya a hacerme el documento de identidad y mi mamá ya no dejó que me fuera".

Respecto al primer punto, que define el viaje como modo de descubrimiento, como forma de explorar el mundo y como medio de relacionarse con la alteridad, no es difícil hacer un paralelismo con las visiones de ayahuasca en las que, entre otras cosas, se visitan y descubren lugares distantes, y se adquieren conocimientos de y sobre los espíritus, y sobre los blancos. Como han destacado varios autores, el chamán es el viajero por excelencia en la Amazonia occidental, operando como mediador y como traductor. Y no se trata únicamente de viajes realizados gracias al uso del ayahuasca o de los sueños, sino también desplazándose por el territorio. La adquisición de poder está asociada a esta movilidad horizontal y vertical (Chaumeil, 1988; Losonczy, 2006), asociación que no tiene tanto que ver, me parece, con adquirir potencias de la alteridad, sino con algo inherente al hecho de viajar: la capacidad de aunar puntos de vista diferentes (Carneiro da Cunha, 1998). Pero no considero que todo viaje tenga necesariamente ese carácter chamánico. Aunque analíticamente se podría establecer una analogía entre el chamán como mediador cósmico y quien aprende sobre el mundo mestizo como mediador con los no indígenas, cada uno de ellos como detentador de conocimientos específicos necesarios para tratar con la alteridad, para los Yaminawa este paralelismo no tendría mucho sentido. Es cierto que al "blanco", como elemento radical de alteridad, le es atribuida una potencia y una eficacia que son aprovechadas por medios chamánicos, como demuestra la incorporación de objetos de los blancos en los cantos kuxuiti, medio chamánico por excelencia para actuar en el mundo (Townsley, 1984). Sin embargo, en un sentido muy específico, para los Yaminawa hay una oposición clara e indiscutible entre la forma genérica de ser de los blancos y mestizos, y el chamanismo: una de las características que marca el mundo de los mestizos, y que les apasiona, es el de las fiestas, regadas de masato, "trago" o cerveza, animadas por la música y marcadas por los juegos de seducción. Y los alimentos de los mestizos, especialmente el alcohol, incluyendo el masato, y el azúcar, son incompatibles con el poder chamánico; es más, son entendidos como la causa de su actual decadencia (Pérez Gil, 2006).

Sea como fuere, la fascinación por el mundo de los mestizos está siempre matizada o limitada, de un lado, por una crítica moral a los mismos, y de otro, por la me- 
moria de los parientes, y entroncamos aquí con el segundo aspecto al que hacía antes referencia. Es siempre la tristeza que se genera en los seres queridos por el hecho de estar lejos la razón explícita para volver.

El tránsito entre ciudad y aldea, en el caso de las estancias largas, individuales y marcadas por un corte de la comunicación, no se reduce a un simple desplazamiento espacial; los Yaminawa suelen hablar de ello como un proceso de "acostumbrarse". Primero las personas se "acostumbran" a vivir en la ciudad; luego vuelven a acostumbrarse a vivir en la aldea. Ese "acostumbrarse" a la ciudad implica utilizar sólo el español como medio de comunicación, aprender el uso de tecnologías, e incluso tener una mujer (o un marido) mestiza, por ejemplo, y es la razón por la cual muchas estancias en lugares lejanos son demoradas. Salvo en el caso de algunos ancianos, que no se acostumbran a la ciudad y prefieren no salir de la aldea, y algunos niños que han crecido durante los diez últimos años en Atalaya y dicen no poder acostumbrarse ya a la aldea, nadie parece tener mucho problema en acostumbrarse alternativamente a un lugar y a otro, a pesar de las diferencias que existen. El habituarse a los modos, al lenguaje, a los alimentos, a las personas o al trabajo de la "ciudad" no parece implicar dificultades. Lo que lleva a los Yaminawa que pasan años viviendo fuera de la aldea a volver con los suyos no es un extrañamiento que calificaríamos de "cultural" en relación al nuevo ámbito social, como muchas veces se define en nuestro mundo la dificultad para integrarse de aquellos que migran a otros países, o por lo menos no es en esos términos como lo definen los Yaminawa. "Acostumbrarse", en ese sentido de comportarse, hablar, comer, casarse con nawa y como nawa ${ }^{24}$, no supone un problema; lo que limita estas estancias en el exterior social es el parentesco o, mejor dicho, la posibilidad del olvido del parentesco. En otros términos, el problema para los Yaminawa no es tanto transformarse en "otro", adquirir otras costumbres, aquello que definimos como "cultura"; el problema surge cuando una estancia demasiado larga y la incomunicación ponen en riesgo las relaciones de parentesco. Recordemos que, de un lado, a quienes no dan noticias se les da por muertos; de otro, la tristeza generada por la ausencia de seres queridos es un estado patológico. La ausencia y la incomunicación demasiado prolongadas llevan sea a la muerte imaginada de quien se ausenta, sea a la potencial muerte real de los que quedan ${ }^{25}$. La persona, viva, yaminawa es en la medida en que participa de su red de parentesco.

\section{Entre la aldea y la ciudad}

Es de notar que a diferencia de otras aldeas de la región, que cuentan, por ejemplo, con energía eléctrica gracias a la instalación de placas solares, con pozos, con escuelas en funcionamiento y en muchas ocasiones con algún pequeño comercio, en

24 El término que los Yaminawa traducen como "acostumbrarse" es wëyai. El caso de los Huni Kuin es muy sugerente, dado que se refieren a ese acostumbrarse a otras formas de vivir como yudawa, literalmente "hacer su cuerpo" (Lagrou 2007: 474). En la Amazonía, transformarse en mestizo es, como cualquier otro proceso de desarrollo de capacidades y cualidades ético-estéticas, un asunto somático (Kelly, 2005).

25 Un caso dramático me fue relatado recientemente en 2017, con ocasión de una breve estancia en Atalaya. Un hombre de alrededor de 60 años se suicidó tras la muerte de su hijo. Es el único caso de suicidio que escuché, y quienes me hablaron de ello lo achacaron a la tristeza provocada por el fallecimiento del hijo. Los estados de tristezas duraderos, especialmente los ocasionados por la muerte de alguien querido, son especialmente temidos porque se considera que pueden llevar a la muerte. 
Raya, la aldea más alejada de las que existen en el Inuya y Mapuya, no hay energía eléctrica, el pozo está inutilizable, la escuela no funciona la mayor parte del tiempo y raramente llega hasta allí quien venda mercancías ${ }^{26}$. En ese sentido, el contraste con la ciudad es más marcado que en otras comunidades nativas de la zona, y así lo expresan especialmente quienes vienen de fuera, como por ejemplo las esposas ashaninka de algunos Yaminawa, que se quejan de lo "poco animada" que es esa comunidad.

Esta noción de la "animación" es una de las que diferencian aldea y ciudad. Pero no se trata de ámbitos contrapuestos, ni mucho menos, de forma global. En Atalaya, aunque las familias yaminawa están relativamente esparcidas por la ciudad, con una relativa concentración en los barrios mayoritariamente indígenas de Floresta y Barrio Junín, hacen una vida, digamos, "comunitaria". Todo transcurre como si una aldea se hubiese establecido en la ciudad, en lo que se refiere al tipo de vida que las personas llevan allí. Da la impresión de que estuvieran en su propio espacio y el resto de la ciudad poco importase, o importase solo circunstancialmente. Como ha notado Calavia, no se trata tanto de haberse trasladado a la ciudad, sino de haber trasladado la aldea a la ciudad (Calavia, 2004:128). Es cierto que se ven obligados a trabajar, porque "en la ciudad todo se tiene que pagar", pero la mayor parte de su tiempo continúa transcurriendo entre parientes: se apoyan y ayudan, prestándose dinero, haciendo circular los alimentos, a pesar de su escasez; se van a pescar juntos cuando alguien consigue algo de gasolina, o a emborracharse en cuanto uno de ellos recibe un pago; los jóvenes se van juntos a la discoteca, y las mujeres se bañan y lavan la ropa juntas en casa de quien haya conseguido pagar el suministro de agua; quienes llevan más tiempo en la ciudad ayudan a encontrar trabajo a quienes llegan para pasar algunas semanas. No son raros los domingos en que se van, si no todos sí una buena parte, a tomar juntos masato a casa de una de las jóvenes, casada con un ashaninka y que cuenta con una roza lo suficientemente grande como para fabricar esa bebida con cierta frecuencia. Todo ello sin contar con las continuas visitas, simplemente para charlar un rato. Además, nunca faltan una o dos familias llegadas del Mapuya, por razones diversas, que se establecen durante días o semanas en las cocinas de sus parientes radicados en Atalaya. De hecho, la vida en común parece en ocasiones más intensa que la de la aldea, por la falta de espacio y recursos, lo que hace que todo se tenga que compartir. Igualmente, cuando trabajan lo suelen hacer varios juntos, tanto hombres como mujeres. Si bien es cierto que en la ciudad se relacionan con varias otras personas, no lo es menos que las relaciones prioritarias, más frecuentes e intensas son las que se tienen con los propios parientes.

En ese sentido, las residencias yaminawa establecidas en Atalaya operan como una extensión de la aldea. No solo porque quienes llegan de la aldea encuentran allí cobijo durante sus viajes a la ciudad, sino también porque existe una intensa circulación entre la ciudad y la aldea, y no únicamente de personas: en el sentido aldeaciudad circulan principalmente alimentos de la chacra y del monte, pero también

26 A diferencia de lo que ocurre en caseríos y comunidades de río abajo, en el Inuya y Urubamba (Hewlett, 2013), en Raya no hay nadie que se dedique al comercio. Antes, los madereros casados con mujeres yaminawa eran fuente de productos manufacturados, pero siempre a cambio de trabajo, a lo que la mayoría de las personas de la aldea era reluctante. Durante los meses que pasé en 2013, dos jóvenes yaminawa, recién casados con mujeres de Atalaya que tenían comercios allí, empezaron a realizar viajes a Raya llevando mercancías, principalmente "trago", para vender en la aldea a cambio de gallinas, carne de caza y motelos. Por lo demás, antes que comprar en los caseríos y comunidades de río abajo, los Yaminawa prefieren hacerlo en Atalaya. 
remedios vegetales (disa); en el sentido ciudad-aldea circulan mercancías de diverso tipo. En última instancia, en tanto que fuentes de recursos diferenciados, la ciudad y la aldea mantienen entre sí una relación de oposición inversamente simétrica, y es por eso por lo que se complementan: si la ciudad es un lugar de abundancia de objetos y escasez de alimentos, la aldea es un espacio de abundancia de alimentos y escasez de objetos.

Esta estrecha relación entre ciudad y aldea no es algo exclusivo de los Yaminawa. Otros autores ya han notado el hecho de que la distinción entre lo rural y lo urbano es difícil de establecer en la región amazónica. Las ciudades en esta parte del mundo, lejos de ser espacios y unidades claramente diferenciados geográfica, económica y socialmente, forman parte, en realidad, de complejas redes sociales que las extrapolan (Pinedo-Vasquez y Padoch, 2009). En la Amazonía peruana, la ciudad y la aldea parecen sobreponerse a la ideología de raza descrita por Peter Gow (2003) en la que "blanco" e "indígena" constituyen los dos polos de un contínuum, el primero asociado al sector comercial y el segundo al de subsistencia. La conexión entre economía e identidad descrita por Gow tiene, por lo tanto, una traducción topográfica. Mi impresión es que el viaje para los Yaminawa es también un tránsito entre esos dos polos: quien viaja a la ciudad realiza también una transición ontológica, que es por otro lado revertida, parcialmente, al volver a la aldea. Cuanto más tiempo se permanezca en la ciudad, o cuanto más frecuentes sean los viajes allí, más se tenderá al polo "blanco"; pero mientras se mantengan vivas las relaciones de parentesco, el polo indígena continuará activo.

Queda claro que viajar - sean viajes cortos o con estancias prolongadas, como expliqué anteriormente - no es simplemente desplazarse entre un lugar y otro, sino que opera también como un proceso constituyente de la persona (Aporta, 2004; Pissolato, 2007), que tiene siempre a otras como referencia y punto de conexión.

Entre los Yaminawa el camino es productivo en diversos sentidos. No se trata tanto de un proceso de construcción de la persona en el transcurso del caminar, como ha descrito Pissolato (2007) en relación a los Mbya, o, si lo es, se trata de algo relativamente indirecto. Lo que importa en el camino es con quién se encuentra uno. Ingold (2007) enfatiza que en el caminar, o en el navegar, existe una interacción intensa con el medio y ello forma parte inherente del movimiento. En los viajes de los que hablo ${ }^{27}$ se trata fundamentalmente de un medio sociológico marcado por el encuentro con personas de otros grupos indígenas, mestizos y blancos. Cualquier desplazamiento es una especie de rosario: el viaje está marcado por las continuas paradas en casa de un pariente que vive un poco más abajo, para charlar un rato; en una aldea amahuaca para dormir o conseguir un poco de yuca; en un caserío mestizo para comprar algo de combustible; o en una comunidad para cambiar la canoa en la que se viaja por otra más consistente que permita enfrentar las aguas menos tranquilas del Urubamba. Todas esas paradas implican tratar con personas, a veces conocidas, otras desconocidas, intercambiar informaciones, llegar a acuerdos, cambiar o recibir alimentos, obtener ayuda, conocer a nuevas personas y darse a conocer, hacer negocios, establecer alianzas. Los casos de brujería son también interpretados, en ocasiones, como consecuencia de estos encuentros. El camino está básicamente marcado por relaciones, a veces buscadas y otras evitadas, como cuando se prefiere dormir en la playa aún a riesgo de ser pillado por una tormenta durante la noche, a hacerlo en

27 En los desplazamientos por la selva, las interacciones relevantes se dan con animales, plantas y espíritus. 
una comunidad específica por miedo a ser envenenado. Estos desplazamientos recuerdan, sin duda, los mitos que consisten básicamente en el vagar un tanto azaroso del héroe, durante el cual se va encontrando con diversos seres (Calavia, 2006:341). Se trata de encuentros, a veces, placenteros y fructíferos, y otras, marcados por el peligro y la violencia.

Este conjunto de movimientos, aparentemente azarosos, caóticos, diversos, deben ser entendidos desde una perspectiva fractal, como manifestaciones a diversa escala, de distinta duración y carácter, de una tensión u oscilación entre la semejanza y la otredad. ¿Qué producen esos movimientos que atraviesan espacios de alteridad? Creo que simplemente la propia experiencia de la alteridad: se experimenta no solo estar con otro, sino también ser como otro. Se trata, ante todo, de "recorridos corporales" (Vilaça, 1999): se vive, se habla, se come con y como otro, con y como un diferente. Todo ello para después volver al lugar de donde se salió, pero transformado. De ahí las eventuales reivindicaciones de muchos de los hombres que tuvieron esas experiencias más largas — que "se acostumbraron" con el mundo de los nawa, como expliqué antes_-, de que no son yaminawa, sino mestizos. La transformación que se deriva del contacto con los otros es una cuestión ontológica y no de identidad: el problema para ellos no tiene que ver con lo que los define como "yaminawa", o sea, con la expresión de trazos que se puedan interpretar como propios de la "cultura yaminawa", sino con las capacidades, cualidades éticas, atributos y características que las personas manifiestan. Diferentes contextos y relaciones exigen formas diferentes de agencia. Creo que es a causa de esta transitividad ontológica, generalizada en la Amazonía peruana, por lo que el concepto de mestizo, al fin y al cabo una categoría que enfatiza la hibridez, tiene un rendimiento sociológico tan importante ${ }^{28}$.

\section{Los viajes y la experiencia del parentesco}

Antes me referí a la dinámica sociopolítica de las continuas fisiones y fusiones. En una interpretación de corte estructuralista, Calavia (2002) la considera como un mecanismo que crea una configuración de multiplicidad de grupos tal que permite casarse a una distancia adecuada: se trata, en última instancia, de generar una alteridad aceptable, que contenga la diferencia necesaria para la continuidad de la reproducción social, apartando el fantasma de una endogamia infértil, al mismo tiempo que elimina el riesgo implicado en una alteridad excesiva. Esa dinámica operaría como si se tratara de extraer alteridad de la semejanza a través de la separación, generando una topografía de distancias sociales tales que permitan conciliar fertilidad y seguri-

28 En las últimas décadas, la etnología indígena ya ha demostrado etnográficamente y teorizado ampliamente sobre el carácter constituyente de la alteridad en las socio-lógicas de las tierras bajas de América del Sur (Carneiro da Cunha y Viveiros de Castro 1985; Chaumeil 1999; Fausto 1999; Menget 2001). En el caso concreto de los pano, ver, por ejemplo, Erikson (1996) y Lagrou (2007). Aunque discutirlo de forma detallada está más allá del propósito de este artículo, sugiero que la forma en la que los Yaminawa se relacionan con la posibilidad de ser mestizo se enmarca dentro de esta lógica. En la medida en que la "identidad" no es un elemento de la ontogénesis, y que cada persona es el producto de una sucesión de transformaciones intencionales, "ser mestizo" no es más que una posibilidad, sumamente atractiva, eso sí, de ser y actuar. Ser mestizo alude, en este caso, a tener determinadas capacidades asociadas especialmente con obtener cosas. Argumenté en otro lugar (Pérez Gil, 2006) que el límite de esta posibilidad de transformarse en mestizo está definido por la crítica moral que los Yaminawa les hacen, a causa de su mezquindad intrínseca, que entra en contradicción con los principios en torno de los cuales se construyen las relaciones de parentesco. 
dad. Por su parte, Townsley (1994) nos ofrece una explicación histórica, en la medida en que esta dinámica de fisiones y fusiones es interpretada como la consecuencia del boom del caucho: en función de la caída poblacional que provocó y la desestructuración social que resultó de ello, los diferentes grupos no tuvieron más remedio que juntarse para poder sobrevivir, lo cual está en la base de la inestabilidad sociológica que podemos observar hasta hoy en día. Sin poner en duda estas interpretaciones, que elucidan dimensiones fundamentales de los procesos de fisión y fusión, por mi parte, me interesa centrarme en cómo los Yaminawa hablan de ellos y de sus viajes; qué es, en última instancia, lo que los motiva. Sus narraciones y comentarios giran siempre en torno a la experiencia — complementaria, diría - de la alteridad y del parentesco, como se desprende de lo que fue descrito hasta ahora.

Las diversas circunstancias que presenté conforman diferentes aspectos de la constitución de un parentesco configurado por tendencias que no operan necesariamente en el mismo sentido todo el tiempo y que presentan, en varias situaciones, dilemas. Y eso ocurre en diversas dimensiones.

En lo que se refiere a las actividades productivas de las familias, esa oscilación se genera por la importancia que tiene tanto aquello que se produce en la comunidad como las mercancías que deben obtenerse en el exterior. La necesidad de obtener esas mercancías lleva a las familias ora a viajar al monte para obtener recursos como madera o carne de caza-, ora a viajar a la ciudad, para venderlos y realizar compras. Pero la oscilación se produce también en otro sentido. El conseguir trabajo, y por lo tanto dinero, es lo que lleva a muchos Yaminawa a viajar a ciudades o a trasladarse a otras comunidades río abajo, como cuando varias familias se fueron a vivir a Floresta. Sin embargo, la imposibilidad que encuentran en estos lugares para sustentarse, por falta de caza, pesca y tierra para hacer una chacra ${ }^{29}$, es una de las razones que les induce a volver a Raya. Se encuentran atrapados en un dilema: ir a la búsqueda de trabajo para obtener mercancías - lo cual implica unas condiciones precarias de vida, especialmente alimentares, ya que nunca se gana lo suficiente-, o vivir en Raya, lo que les permite producir los alimentos necesarios para ser autosuficientes, pero donde es más difícil obtener artículos manufacturados. Ambos aspectos, las mercancías y la producción de alimentos de la chacra y del monte, son al mismo tiempo objeto de deseo y aspecto necesario para viabilizar el sustento de las familias y la reproducción social. Es más, ambos son al mismo tiempo condición y producto de las relaciones de parentesco. Retomo aquí la idea del viaje como experiencia de transitividad ontológica. Mencioné anteriormente el papel constituyente de la alteridad en las sociedades indígenas y que el convertirse en mestizo podría ser leído a partir de esta llave interpretativa. Si para los Yaminawa, como argumento, determinados viajes tienen que ver con la experiencia de transformarse en mestizo,

29 Como me insistieron en muchas ocasiones las familias que vivieron en Floresta, allí tenían más acceso a bienes manufacturados, pero el pedazo de tierra del que disponían era totalmente insuficiente, y la pesca y la caza escaseaban, así que hablan de aquella experiencia como de penuria alimentaria. El contraste entre Raya y otras comunidades río abajo era tema común cuando conversaba especialmente con las mujeres ashaninka casadas con Yaminawa y que viven ahora en el Mapuya — situación novedosa en relación a mi experiencia de campo entre 2000 y 2003, cuando los únicos no-yaminawa que había eran algunos madereros. Ellas siempre comentaban que había mucha diferencia en relación a sus comunidades de origen, en el Ucayali y el Urubamba. Si por un lado se quejaban de que en Raya no hay “animación”, es silencioso, hay poca gente, está muy alejado de la ciudad y faltan infraestructuras como luz eléctrica, por otro lado reconocen como un aspecto de peso que en el Mapuya no hay inundaciones y, sobre todo, se pueden tener chacras tan grandes como se quiera; hay pesca y caza y, en definitiva no se hambrea. Eso hace de Raya un lugar donde se puede vivir bien. 
en el sentido de adquirir sus capacidades para obtener mercancías, ello no tiene que ver con las mercancías en sí, sino con su papel para la sustentación de la familia, o sea, para la producción y reproducción del parentesco. "Transformarse" en mestizo, paradójicamente, es una condición para la reproducción social yaminawa.

Eso en lo que se refiere a la dimensión productiva. Pero los dilemas, quizás más acuciantes, se les plantean a los Yaminawa cuando se trata de las relaciones intersubjetivas. La vida comunitaria, lejos de ser un oasis de solidaridad y armonía — aunque estos ingredientes no falten - está permeada de conflictos y tensiones. Las fisiones que ocurrieron en el pasado entre grupos diferentes son su manifestación más dramática, pero en el presente tienen otras consecuencias. Se desea estar con los parientes y, sin embargo, al mismo tiempo, es difícil convivir con ellos. Malentendidos, roces, sinsabores... forman parte del cotidiano. Wakësuya, una mujer txitonawa, lo describía de forma muy gráfica cuando me contaba cómo era su vida en el monte, con anterioridad al contacto, pocos años antes. Las familias que componían el pequeño grupo no estaban todo el tiempo juntas, sino que vagaban por un territorio continuo. Si cada poco tiempo se producían encuentros entre dos o tres familias que pasaban a convivir por algunos días, esto no duraba mucho y al poco tomaban derroteros diferentes. Se podría pensar que esta práctica responde a diversos factores, tales como la facilidad para recolectar y cazar o el resultar más invisibles y por lo tanto tener algo más de seguridad. Sin embargo, lo que ella enfatizaba es que surgían continuamente rencillas: celos entre parejas y enfados por la mezquindad del otro con la comida o con los objetos robados en los campamentos madereros son las más mencionadas. Y estas continúan siendo, básicamente, las razones por las que los Yaminawa deciden poner algo de distancia en relación a sus corresidentes, a veces simplemente yéndose a vivir un poco alejados del núcleo central de la aldea, o al otro lado del río; en otras, trasladándose a una comunidad de Yuruá, a Atalaya o a Sepahua. Esa es la experiencia paradójica del parentesco. Si uno de los principales motivos para viajar es visitar o establecerse con parientes, a los que se añora, y que por esa tendencia centrífuga se encuentran lejos, otro de los motivos es el deseo de separarse, por lo menos temporalmente, de unos parientes con quienes la convivencia genera frustración, en gran medida porque se considera que no siempre se comportan como deberían; las relaciones de parentesco que se viven, no son las que se debería y desearía vivir. Estas últimas quedan relegadas al cielo, paraíso consanguíneo, donde no hay necesidad de alianza porque no hay fertilidad; donde no hay necesidad de cazar - y por lo tanto de ingerir alteridad y riesgo- porque solo se comen dulces y olorosas piñas que crecen sin la intervención de los espíritus.

Una de las implicaciones que me gustaría destacar es que el vivir separado no deconstruye las relaciones de parentesco. Como ha argumentado Carid (2007), existen otros mecanismos diferentes a la corresidencia en la producción del parentesco, tales como la memoria, construida y recreada en los cantos yama yama o en las narraciones sobre acontecimientos pasados; y la comunicación y circulación de noticias presentes, sea por radio, lo que ocurre dos veces al día, con la participación de toda la red de asentamientos yaminawa, tanto en las CCNN como en las ciudades, o por teléfono móvil. Los procesos que constituyen las participaciones intersubjetivas, la red de mutualities of being que conecta a las personas, según la reciente formulación de Sahlins (2013) para definir los sistemas de parentesco, no derivan únicamente, en el caso de los Yaminawa, de la constitución de la consanguinidad por medio de la construcción de cuerpos consustanciales, sino también de las memorias y los afectos. 
Los viajes constituyen, a este respecto, uno de los mecanismos que tienen el efecto de actualizar las conexiones de mutualidad de parientes que viven distanciados. Dado que en esta composición en red la oposición dentro/fuera no tiene una dimensión espacial, cada persona tiene una serie de referencias, esparcidas por un territorio relativamente amplio — lugares-sujeto, como los define Calavia (2004) - y las visitas a unos y otros forman parte de cómo los Yaminawa viven y construyen esas relaciones de parentesco (Carid Naveira, 2007). La intensidad de la relación no corresponde necesariamente con una mayor cercanía espacial. No es infrecuente que se idealice a aquellos que están lejos. Uno de los temas sobre los que más le gustaba hablarme a Txaiyabawade, uno de los ancianos de Raya, era la cantidad de parientes que tenía lejos; se recreaba enumerando cada uno de los lugares a los que podría ir sin problema porque sería bien recibido: las comunidades del Yuruá, Breu, Atalaya, Pucallpa, Sepahua... En todos ellos tendría cobijo y alimento, porque en todos ellos tiene parientes queridos y que le quieren.

Los viajes, lejos de ser desestructuradores o producto de una situación desestructurada por las circunstancias y condiciones generadas por el contacto, constituyen un aspecto central de cómo los Yaminawa viven sus relaciones de parentesco y, por lo tanto, de su forma de estar en el mundo y, concretamente, en el espacio, que es ante todo un espacio social. Aunque en otro sentido, Feather (2012) también hace referencia, en relación a los Nahua, a esa naturaleza pendular de los viajes, ya que oscilan entre la construcción y deconstrucción de las relaciones sociales. En ese caso es, de un lado, la necesidad de olvidar a los muertos recientes y, de otro, el deseo de producir relaciones sociales con los representantes de una alteridad poderosa, los no-indígenas, lo que les lleva a emprender sus imprevisibles odiseas. En cualquier caso, se trata de relaciones de parentesco - las que se tienen con los vivos y las que se tienen con los muertos - atrapadas en dilemas que los viajes permiten, aunque temporal y precariamente, soslayar.

\section{9. ¿Comunidad Nativa?}

Confrontada ante la experiencia que los Yaminawa tienen del territorio y del vivir con otras personas, la noción de Comunidad Nativa parece constituir, a primera vista, prácticamente su antítesis. Esta noción presupone un conjunto poblacional relativamente estable y eminentemente rural, limitado a quienes viven en el interior del territorio demarcado. Como establece el Decreto-Ley n ${ }^{\circ} 22175^{30}$, las Comunidades Nativas "tienen origen en los grupos tribales de la Selva y Cejas de Selva y están constituidas por conjuntos de familias vinculadas" por tres elementos: el idioma, los caracteres culturales y sociales y "la tenencia y usufructo común y permanente de un mismo territorio, con asentamiento nucleado o disperso".

A pesar de la extrema movilidad yaminawa, causada por la dilemática experiencia del parentesco en sus dimensiones productiva, social y afectiva, la figura administrativa y política de la Comunidad Nativa, como un espacio estático, de contornos geográficos y demográficos fijos, y que presupone una identificación entre "etnia" y territorio, no es, lejos de lo que se podría pensar, algo totalmente inadecuado. Si

$30 \quad$ La Ley 22175, "Ley de Comunidades Nativas y de Desarrollo Agrario de la Selva y de Ceja de Selva", aprobada en 1978, rige actualmente la titulación de las Comunidades Nativas en Perú. 
es verdad que, como señala Calavia $(2004,2015)$ respecto del concepto de Terra Indigena en Brasil, su definición no llevó en consideración las nociones indígenas sobre territorialidad —asumiendo una conceptualización geográfica, histórica y económica del espacio pensado en términos de lugares-objeto-; o sobre el vivir juntos - presuponiendo un concepto de comunidad, internamente solidaria y coherente, vuelta sobre sí misma y que opera por una suerte de solidaridad orgánica-, no es menos cierto que los pueblos indígenas se han apropiado y beneficiado de esta política estatal, y que a pesar de las inadecuaciones y desfases conceptuales, la han hecho jugar a su favor, por así decirlo. Uno de los autores que ha demostrado fehacientemente esto es Peter Gow (1991), al evidenciar la importancia de la Comunidad Nativa para la emancipación de los Yine en relación al sistema de explotación al que estuvieron sometidos durante toda la época colonial. La Comunidad Nativa es al mismo tiempo producto del parentesco y su mecanismo de defensa. Por su parte, para el caso brasileño, Calavia muestra que los Yaminawa han desarrollado una concepción "híbrida" de territorio, que se nutre tanto de su memoria histórica como de la concepción jurídica que fundamenta la ordenación de las Terras Indígenas. La territorialidad constituida por la ley es considerada por los Yaminawa vital para su supervivencia, y el uso político y práctico de los conceptos que la fundamentan no solo no anula modelos y prácticas preexistentes relativas al espacio, sino que se articula con ellos (Calavia, 2015: 275).

Si otros lugares fuera de la aldea de Raya son lugares-sujeto porque en ellos se encuentran "regados" — por usar la expresión usada en español por los Yaminawalos seres queridos, también lo es el Mapuya en su conjunto. Un anciano aseveraba, con una cierta nostalgia, que nunca podría dejar el lugar por la cantidad de recuerdos que aquel río entraña de sus seres queridos, muertos y enterrados en esos bosques.

Paralelamente al aspecto afectivo, la Comunidad Nativa constituye la condición necesaria para la subsistencia y, por lo tanto, para la reproducción social y el parentesco. Hace quince años la disponibilidad de tierra y el acceso a bosques y aguas donde había abundancia de animales y peces era algo que los Yaminawa daban por sentado. Aunque hoy en día la disponibilidad sigue siendo la misma ${ }^{31}$, algunas personas parecen haber tomado conciencia de que eso no será siempre necesariamente así, de que puede cambiar. Comentarios en este sentido suelen ser realizados por quienes, por haber vivido en comunidades río abajo y en la ciudad, conocen bien la realidad de la escasez de alimentos en estos lugares. Por otro lado, en función de la llegada de una Compañía petrolera a la región y la intensificación de las actividades de la ONG ProPurús, que en sus visitas a Raya trata con la comunidad cuestiones ambientales, un discurso, antes inexistente, sobre la importancia de conservación del medio está empezando a hacerse presente entre algunos hombres yaminawa como Napo, que, por su papel como líder, tiene un contacto más intenso con estas organizaciones. Cada vez más, Raya es visto por sus habitantes como un lugar que, a pesar de sus muchas carencias en términos de infraestructura, es un lugar privilegiado en lo que se refiere a recursos. Y estos recursos son importantes tanto para quienes viven en el río, como para quienes viven en la ciudad.

En cierto sentido es como si, a través de estos movimientos, más que dispersarse o disgregarse, descaracterizándose, la Comunidad, en términos de colectividad

31 El único cambio al que hicieron referencia en 2013 es que hace años que no se ven bandos de huanganas, fenómeno que atribuyen a la explotación maderera de empresas en años anteriores. 
humana constituida por relaciones de mutualidad y asociada a un territorio, se expandiese, por un lado, y se tornase más evidente por otro, ya que los lazos que unen a las personas manifiestan una gran solidez a pesar de ser puestos a prueba por la distancia. Por otro lado, la Comunidad Nativa es un punto de referencia (Godelier, 2001) frente a ese devenir incansable del movimiento; es el lugar al que volver, aunque sea para partir nuevamente poco después, el lugar que garantiza la continuidad del movimiento y, por lo tanto, del parentesco.

A este respecto, no podemos olvidar, finalmente, el papel contra el Estado de los desplazamientos (Clastres 2003). El nomadismo ha sido tradicionalmente interpretado en la antropología como un mecanismo para sustraerse al control estatal, como forma de resistencia y de ejercer la libertad, y ha adquirido un estatus teórico y político especialmente relevante a partir de los trabajos de Deleuze y Guattari (Engebrigtsen, 2017). Si la Comunidad Nativa garantiza las condiciones necesarias para la producción y reproducción de las relaciones de parentesco, los viajes, no solo son un ingrediente constitutivo de la sociabilidad y mecanismo de actualización de estas relaciones, sino que también operan como un límite — del mismo modo que la crítica moral a los mestizos - a la "integración" en la sociedad nacional. En el caso que nos ocupa, me parece que la Comunidad Nativa, como figura del Estado y de la estabilidad, y los viajes, como constitutivos de la forma yaminawa de estar en el mundo y figura del movimiento, son, no contradictorios, como podría inferirse del enunciado de la ley, sino complementarios.

\section{Referencias bibliográficas}

Alexiades, Miguel N. (2009). "Mobility and Migration in Indigenous Amazonia: Contemporary Ethnoecological Perspectives - an Introduction", en M.N. Alexiades (Ed.), Mobility and migration in indigenous Amazonia. Contemporary ethnoecological perspectives. New York / London: Berghahn Books.

Aporta, Claudio (2004). "Routes, trails and tracks: Trail breaking among the Inuit of Igloolik". Études/Inuit/Studies, 28 (2): 9-38. doi : 10.7202/013194ar

Calavia, Oscar (2002). "Nawa, Inawa". Ilha. Revista de Antropologia, 4 (1): 35-54. doi: http://dx.doi.org/10.5007/\%25x

- (2004). "Mapas Carnales. El territorio y la sociedad Yaminawa", en A. Surrallés y P. Hierro (Eds.), Tierra adentro. Territorio indígena percepción del entorno. Copenhague: IWGIA.

- (2006). O nome e o tempo dos Yaminawa: Etnologia e história dos Yaminawa do rio Acre. São Paulo, Rio de Janeiro: Editora UNESP/ISA/NUTI.

- (2007). "Topología de los viajes amazónicos". Revista de Occidente, 314-315: 43-58.

- (2015). "O território, visto por outros olhos". Revista de Antropologia, 58 (1): 257-284. doi: http://dx.doi.org/10.11606/2179-0892.ra.2015.102108

Carid Naveira, Miguel (2007). Yama yama: os sons da memória. Afetos e parentesco entre os Yaminahua. Tesis doctoral. Programa de Pós-Graduação em Antropologia Social. Universidade Federal de Santa Catarina.

Carid Naveira, Miguel; Pérez Gil, Laura (2013). "Devenir otro, devenir pariente: las masateadas yaminahua (Amazonía peruana)". Revista Española de Antropología Americana, 43 (1): 267-284. doi: http://dx.doi.org/10.5209/rev_REAA.2013.v43.n1.42318 
Carneiro Da Cunha, Manuela (1978). Os mortos e os outros. Uma análise do sistema funerário e da noção de pessoa entre os índios Krahó. São Paulo: Hucitec.

- (1998). "Pontos de vista sobre a floresta amazônica: xamanismo e tradução". Mana, 4 (1)

Carneiro da Cunha, Manuela; Viveiros de Castro, Eduardo (1985). "Vingança e temporalidade: os Tupinambá". Journal de la Société des Américanistes, LXXI: 191-208. doi DOI : $10.3406 /$ jsa. 1985.2262

Chaumeil, Jean-Pierre (1988). «Réseaux chamaniques contemporaines et relations interethniques dans le haut Amazone (Pérou)», en C.E. Pinzón, R. Suárez y G. Garay (Eds.), Otra América en construcción. Amsterdam: 46 ICA.

- (1999). "El Otro Salvaje: chamanismo y alteridad". Amazonía peruana, 26: 7-30.

Clastres, Pierre (2003). A sociedade contra o Estado: pesquisas de antropologia política. Rio de Janeiro: Cosac naify.

Déléage, Pierre (2009). Le chant de l'anaconda. L'apprentissage du chamanisme chez les Sharanahua (Amazonie occidentale). Nanterre: Societé d'Ethnologie.

Engebrigtsen, Ada Ingrid (2017). "Key figure of mobility: the nomad". Social Anthropology/ Anthropologie Sociale, 25 (1): 42-54. doi : 10.1111/1469-8676.12379

Erikson, Philippe (1996). La Griffe des Aïeux. Marquage du corps et démarquage ethnique chez les Matis d'Amazonie. Paris: Editions Peeters.

Fausto, Carlos (1999). "Of enemies and pets: warfare and shamanism in Amazonia". American Ethnologist, 26 (4): 933-956. doi: 10.1525/ae.1999.26.4.933

Feather, Conrad (2010). Elastic selves and fluid cosmologies: Nahua resilience in a changing world. PhD Thesis. University of St Andrews.

- (2012). "The restless life of the nahua shaping people and places in the peruvian amazon", en M.N. Alexiades (Ed.), Mobility and migration in indigenous Amazonia. Contemporary Ethnoecological Perspectives. New York/Oxford: Berghahn books.

Ferreira, Fátima (2014). "Eles têm um quintal grande demais para o estado do Acre”. Uma etnografia acerca das estratégias dos índios Jaminawá para sua permanência e trânsito entre suas aldeias e a cidade de Rio Branco - Acre. Monografia de final de carrera. Curso de Ciências Sociais. Universidade Federal de Santa Catarina.

Frank, Erwin (1994). “Los Uni”, en F. Santos Granero y F. Barclay (Eds.), Guia Etnográfica de la Alta Amazonía. Vol. II. Quito: IFEA/FLACSO, 129-237.

Godelier, Maurice (2001). O enigma do dom. Rio de Janeiro: Civilização Brasileira.

Gow, Peter (1991). Of mixed blood. Kinship and history in Peruvian Amazonia. Oxford: Clarendon Press.

- (2003). "'Ex-cocama": identidades em transformação na Amazônia Peruna". Mana, 9 (1): 57-79. doi: http://dx.doi.org/10.1590/S0104-93132003000100004

Hewlett, Christopher Erik (2013). History, Kinship, and Comunidad: Learning to Live Together Amongst Amahuaca People on the Inuya River in the Peruvian Amazon. PhD Thesis. University of St. Andrews.

Ingold, Tim (2007). Lines. A brief history. London \& New York: Routledge.

Kelly, José Antonio (2005). "Notas para uma teoria do "virar branco"”. Mana, 11(1): 201334. doi: http://dx.doi.org/10.1590/S0104-93132005000100007

Kensinger, Kenneth (1998). "Cashinahua”, en F. Santos Granero y F. Barclay (Eds.), Guia Etnográfica de la Alta Amazonía. Vol. 3. Panamá / Quito: Smithsonian Tropical Research Institute / Abya-Yala, 1-124.

Killick, Evan (2008). "Creating Community: Land Titlig, Education, and Settlement Formation Among the Ashéninka of Peruvian Amazonia". Journal of Latin American ans Caribbean Anthropology, 13(1): 22-47. doi: 10.1111/j.1548-7180.2008.00003.x 
Lagrou, Elsje (2007). A fluidez da forma: arte, alteridade e agência em uma sociedade amazônica (Kaxinawa, Acre). Rio de Janeiro: Topbooks.

Lenaerts, Marc (2002). Nos sœurs Manioc et l'étranger Jaguar : diversité et changement des savoirs sur les Etres de la Nature, chez les Ashéninka " de l’Ucayali " (Amazonie péruvienne et brésilienne). Thèse Doctorale. Université Libre de Bruxelles.

Losonczy, Anne-Marie (2006). Viaje y violencia. La paradoja chamánica emberá. Bogotá: Universidad Externado de Colombia.

Menget, Patrick (2001). Em nome dos outros. Classificações das relações sociais entre os Txicáo do Alto Xingu. Lisboa: Assírio \& Alvim.

Pérez Gil, Laura (2006). Metamorfoses yaminawa: Xamanismo e socialidade na Amazonia peruana. Tesis doctoral. Programa de Pós-Graduação em Antropologia Social. Universidade Federal de Santa Catarina.

- (2010). "Cuerpos en transformación: sobre la noción de persona y el control alimentar entre los Yaminawa”. Tellus, 10 (19): 53-82.

- (2011). "Adversários e mediadores: os outros dos Yaminawa no processo de contato", en E. Coffaci de Lima y L. Córdoba (Eds.), Os Outros dos Outros: Relações de alteridade na Etnologia Sul-Americana. Curitiba: Ed. da UFPR, 83-94.

Pinedo-Vasquez, Miguel; Padoch, Christine (2009). "Urban, Rural and In-between: Multisited Households Mobility and Resource Management in the Amazon Flood Plain", en M.N. Alexiades (Ed.), Mobility and migration in indigenous Amazonia. Contemporary ethnoecological perspectives. New York/London: Berghahn Books.

Pissolato, Elizabeth (2007). A duração da pessoa: mobilidade, parentesco e xamanismo mbya (guarani). São Paulo, Rio de Janeiro: Editora UNESP ISA NuTI.

Sahlins, Marshall (2013). What kinship is-and is not. Chicago: The University of Chicago Press.

Santos Granero, Fernando; Barclay, Frederica (1998). "Introducción”, en F. Santos Granero y F. Barclay (Eds.), Guia Etnográfica de la Alta Amazonía. Vol. 3. Panamá/Quito: Smithsonian Tropical Research Institute / Abya-Yala.

Townsley, Graham (1984). "Gasoline song: a shamanic chant of the Yaminahua. An amazonian group of the peruvian lowlands". Cambridge Anthropology, 9 (2): 75-79.

- (1993). "Song Paths: the ways and means of yaminahua shamanic knowledge". L'Homme, 33 (2-4): 449-468. doi: 10.3406/hom.1993.369649

- (1994). "Los Yaminahua”, en F. Santos Granero, F. Barclay (Eds.), Guía Etnográfica de la Alta Amazonía. Vol. 2. Quito: FLACSO/IFEA.

Vilaça, Aparecida (1999). «Devenir autre: chamanisme et contact interethnique en Amazonie Brésilienne». Journal de la Société del Americanistes, 85: 239-260. doi: 10.3406/ jsa.1999.1736

Viveiros de Castro, Eduardo (2009). "The Gift and the Given: Three Nano-essays on Kinship and Magic", en S. Bamford, J. Leach (Eds.), Kinship and beyond. The Genealogical Model Reconsidered. New York \& Oxford: Berghahn Books. 